\title{
PFÉ-EMBEBIÇÃo EM ÁGUA E PORCENTAGEM E VELOCIDADE DE EMERGÊNCIA DE SEMENTES DE PALMITEIRO (1)
}

\author{
MARILENE LEÄO ALVES BOVI (?)
}

\begin{abstract}
RESUMO
Quatro periodos de pré-embebição em água forañi aplicados a frutos e sementes de palmiteiro (Euterpe edulis Mart.) visando determinar seus efeitos na velocidade, na porcentagem e na duração média do processo de emergência. A pré-embebição do fruto foi prejudicial à porcentagem final e velocidade de emergência, provavelmente por permitir maior contaminação por microorganismos patogênicos. A aplicaçăo desse tratamento por dois dias em sementes mostrou efeito benéfico sobre a porcentagem final, nảo sendo, porém, eficiente para acelerar sua emergência. Periodos maiores do que dois dias foram prejudiciais, tanto à porcentagem como à velocidade de emergência. $O$ uso de frutos despolpados acelerou e aumentou a emergência, diminuindo o tempo médio do processo germinativo em comparaçāo com a utilização de frutos nāo despolpados.
\end{abstract}

Termos de indexação: palmiteiro, sementes, pré-embebiçăo, índice de velocidade, emergência.

\section{ABSTRACT \\ WATER IMBIBITION ON HEART OF PALM SEEDS}

Four periods of water imbibition were applied on fruits and seeds of heart of palm plants (Euterpe edulis Mart.) in order to identify the effects of additional water on the standard emergence, speed of emergence index and emergence process duration. Imbibition of fruits showed detrimental effects over the percentage and rate of emergence, probably due to an increasing microorganism contamination. Although imbibition of seeds per two days presented an increase in standard emergence, in comparison with the other treatments, it was not effective to accelerate the process. Seeds, after passing through a fruit decorticage, gave greater and faster emergence, with a considerable decrease of the emergence process duration.

Index terms: heart of palm, imbibition, seed emergence and rate.

(1) Recebido para publicaçăo em 4 de setembro e aceito em 14 de dezembro de 1989.

(2) Seçáo de Plantas Tropicais, Instituto Agronómico (IAC) Caixa Postal 28, 13001 Campinas (SP). Com bolisa de pesquisa do CNPq. 


\section{INTRODUÇão}

O processo germinativo das sementes de palmiteiro (Euterpe edulis Mart.) é bastante lento e desuniforme, iniciando-se a emergência, em condições normais, 30 dias após a semeadura e podendo estender-se até 300 dias do seu início (BOVI \& CARDOSO, 1976 a,b, 1978).

O fruto do palmiteiro apresenta, quando maduro, uma semente completamente formada e apta a iniciar o processo germinativo. $O$ embriâo, embora pequeno, está plenamente desenvolvido, e os dois únicos impedimentos à germinação são a polpa do fruto $e$ a presença de um opérculo seroso que dificulta a penetração de água no interior da semente. A polpa, oleaginosa, mantida ao redor do endocarpo fibroso que reveste a semente, contribui para a diminuição da velocidade de germinação e, por ser um substrato rico para o desenvolvimento de microorganismos, afeta a porcentagem final de emergência obtida. Esses dois fatores exógenos da possivel dormência das sementes dessa palmeira podem ser facilmente superados pelo despolpamento do fruto e pela escarificaçâao do poro vegetativo (BOVI \& CARDOSO, 1976 a,b). Na prática, o simples despolpamento do fruto possibilita aumentar a porcentagem e rapidez de germinaçăo de forma significativa em relaçāo ao uso do fruto não-despolpado (LEĀO \& CARDOSO, 1974; BOVI, 1986).

O despolpamento, feito após a imersão dos frutos em água por três a quatro dias, poderia fazer supor um efeito estimulante do tratamento de pré-embebição sobre a porcentagem final e velocidade de germinação. HARTMANN \& KESTEF (1975) apontam que a emergência de sementes que apresentam normalmente germinação lenta pode ser acelerada por tratamento de pré-embebição em água. O efeito benéfico da préembebição sobre a velocidade de germinação deve-se a ser a absorção de água a primeira etapa do processo germinativo, sendo possivel que as sementes já tenham completado, parcial ou totalmente, essa fase por ocasião do plantio (ADRIANCE \& BRISON, 1967).

Entre os graus de recalcitrância propostos recentemente por FARRANT et al. (1988), o palmiteiro parece ocupar a classe de sementes ditas moderadamente recalcitrantes: toleram uma pequena perda de água através de secagem $e$ apresentam taxa de germinação moderada na ausência de água adicional. A presença de água adicional, através da pré-embebição, poderia funcionar como um acelerador do processo germinativo. Embora existam relatos sobre o efeito da embebição em sementes de plantas tropicais, ditas recalcitrantes, há outros em que esse tipo de resposta não foi encontrado. MADHAVA RAO \& HASSAN (1957), por exemplo, relatam que a porcentagem e a velocidade de emergência 
de sementes de cajueiro (Anacardium ocidentalis) foram favorecidas pela pré-embebição em água por um periodo de dois dias. Por outro lado, FIGUEIREDO et al. (1980) não observaram efeito da préembebição na germinação de sementes de castanha-do-brasil (Bertholletia excelsa), embora se saiba que essas sementes apresentam tegumento permeável à água (MORAES \& MULLER, 1978).

O presente trabalho teve como objetivo estudar os efeitos da pré-embebiçāo na emergência e no vigor de sementes de palmiteiro, procurando aprimorar técnicas fáceis de serem postas em prática por agricultores interessados no manejo sustentado e mesmo no cultivo tecnificado dessa palmeira. $O$ efeito do despolpamento sobre a velocidade, a porcentagem e a duração média do período de emergência pôde, mais uma vez, ser comparado em relação ao fruto inteiro.

\section{MATERIAL E MÉTODOS}

Foram utilizadas sementes de palmiteiro adulto cultivado junto a outros de sua espécie dentro da coleção de germoplasma que o instituto Agronômico mantém na Estaçāo Experimental de Pariqueraçu, litoral sul paulista. As sementes, na colheita, apresentavam maturaçāo uniforme, e foram colhidas no ponto ideal de maturação, ou seja, com coloração preta e luzidia.

$O$ delineamento dos tratamentos empregados foi um fatorial $2 \times 4$, com dois tipos de material de propagação (fruto inteiro e despolpado) e quatro periodos de embebição em água (0, 2, 4 e 6 dias). Os tratamentos foram estudados em um esquema inteiramente casualizado, com quatro repetiçōes, sendo cada parcela composta por cem sementes.

Para a aplicação dos tratamentos previamente estabelecidos, os frutos, imediatamente após a colheita e com umidade inicial em torno de $50 \%$, foram subdivididos em dois lotes, tendo um deles as sementes despolpadas. Para essa operação, os frutos foram acondicionados em sacos plásticos, molhados até a completa saturação, retirado o excesso de água e deixados a sombra, dentro do saco plástico fechado, por três dias. Após esse periodo, foram atritados sobre peneira de malhas grossas, onde se deu a completa separação da polpa da semente. Para os tratamentos de pré-embebição, os frutos e as sementes foram imersos em água, separadamente por parcela experimental, com a temperatura em equilíbrio com a do ambiente.

Após terem sido submetidos aos diferentes períodos de embebição, os frutos e sementes foram tratados com o fungicida Rhodiauran (pó seco com 70\% de dissulfito de tetrametil tiurã) e semeados a $2 \mathrm{~cm}$ de profundidade, em sacos plásticos pretos, de $14 \times 28 \mathrm{~cm}$, cheios com terra de subsolo e colocados em viveiro com $50 \%$ de insolação. Os sacos plásticos foram regados logo após a semeadura $e$, depois, diariamente.

A emergência foi observada todos os dias até o aparecimento da primeira plântula e, a partir daí, semanalmente. A porcentagem final de emergência foi 
determinada 275 dias após a semeadura, quando já por mais de três semanas nenhuma plântula emergiu.

$O$ índice de velocidade de emergência (IVE) foi calculado pelo somatório das razōes do número de plantas emergidas no periodo pelo número de dias da semeadura à emergência, usando-se a fórmula proposta por MAGUIRE (1962). A estimativa da duração média do periodo de emergência foi feita através da adaptação de fórmula proposta por BIANCHETTI \& AMARAL (197\&), sendo calculada pela razão da porcentagem de emergência ( $P E)$ pelo indice de velocidade de emergência (IVE).

Para efeito de análise estatística, os dados de porcentagem de emergência foram previamente transformados em arco seno (raiz de \%/100). Os testes estatísticos foram considerados ao nível de $5 \%$. Devido à existência de interação tipo $x$ embebição e os niveis de pré-embebição serem igualmente espaçados, os efeitos da pré-embebição em água foram estudados, separadamente, dentro de fruto e dentro de semente através de polinômios ortogonais (STEEL \& TORRIE, 1980, e GOMES, 1987). Equações de regressão foram usadas para verificar as tendências dos diferentes caracteres medidos em função do tempo de embebição.

\section{RESULTADOS}

No quadro 1 encontra-se um resumo da análise da variância para os dados de porcentagem de emergência ( $P E$ ) (transformados em valores angulares para a análise estatística), índice de velocidade de emergência (IVE) e duraçāo média do período de emergência (DMPE).

Essa análise revelou interação significativa entre tipo e pré-embebição para todos os caracteres avaliados, sugerindo o estudo do efeito do fator pré-embebição dentro de cada tipo. A pré-embebiçāo, tanto dentro de fruto como dentro de semente, apresentou valores de $F$ estatisticamente significativos para todos os caracteres estudados, com exceção da porcentagem de emergência, onde a pré-embebição dentro de fruto não mostrou significância ao nivel preestabelecido.

O coeficiente de variaçāo do experimento apresentou valores de 8,77 a $12,82 \%$ para os diferentes caracteres estudados, o que, para experimento em viveiro e com material genético pouco melhorado, como é o palmiteiro, está dentro do esperado.

O quadro 2 apresenta as médias dos dados obtidos para porcentagem (PE), índice de velocidade (IVE) e duração média do período de emergência (DMPE) de sementes e frutos de palmiteiro. A emergência de sementes variou, em média, de 44 a $69 \%$ para frutos inteiros e de 72 a $97 \%$ para frutos despolpados (sementes). Da mesma forma, a velocidade de emergência foi bastante superior para as sementes, mostrando um efeito benéfico do despolpamento sobre a porcentagem e rapidez de emergência obtida. A duração média do período de emergência variou de cerca de 132 a 253 dias para os frutos inteiros e de 97 a 126 dias para os despolpados. 


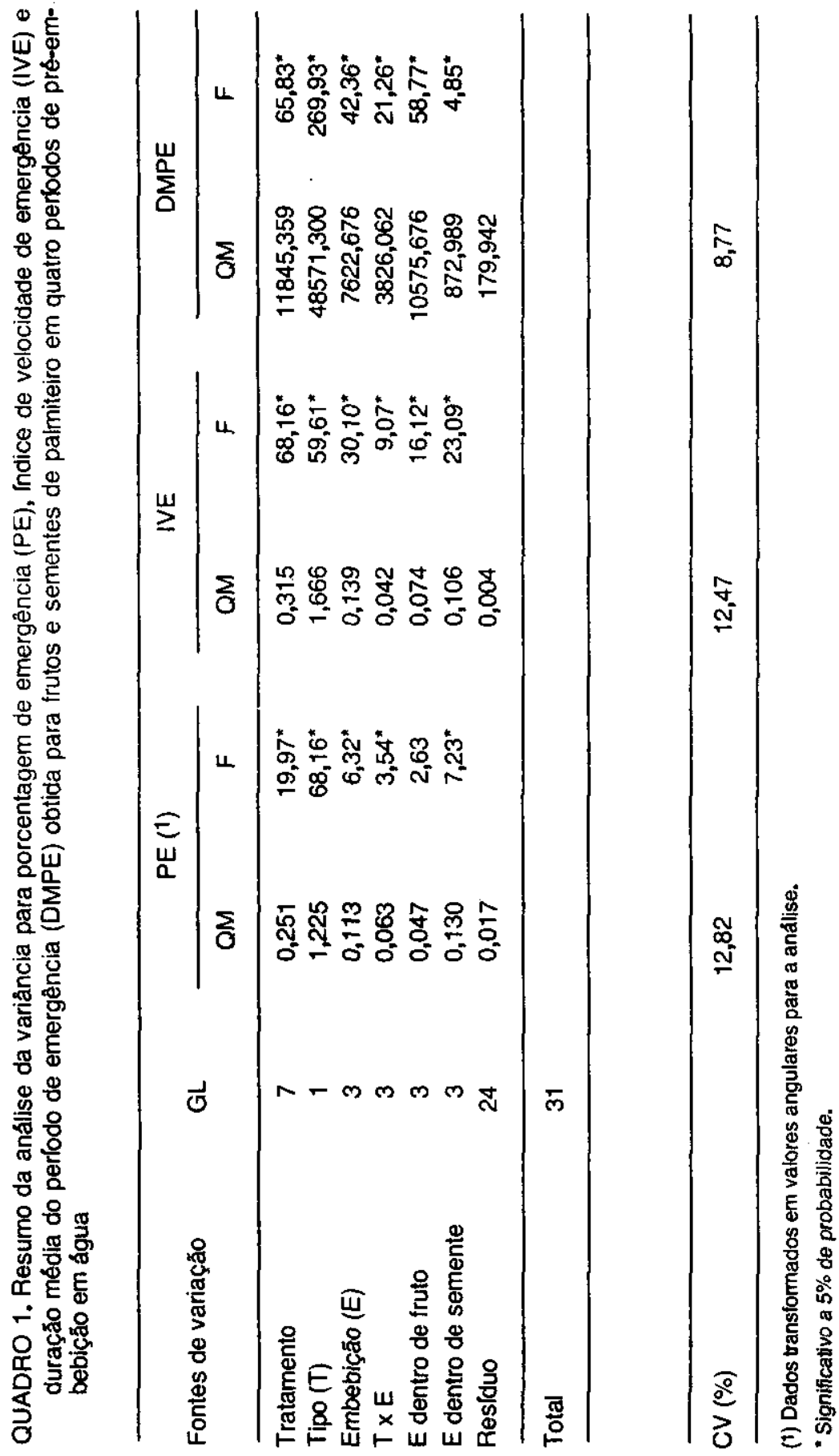




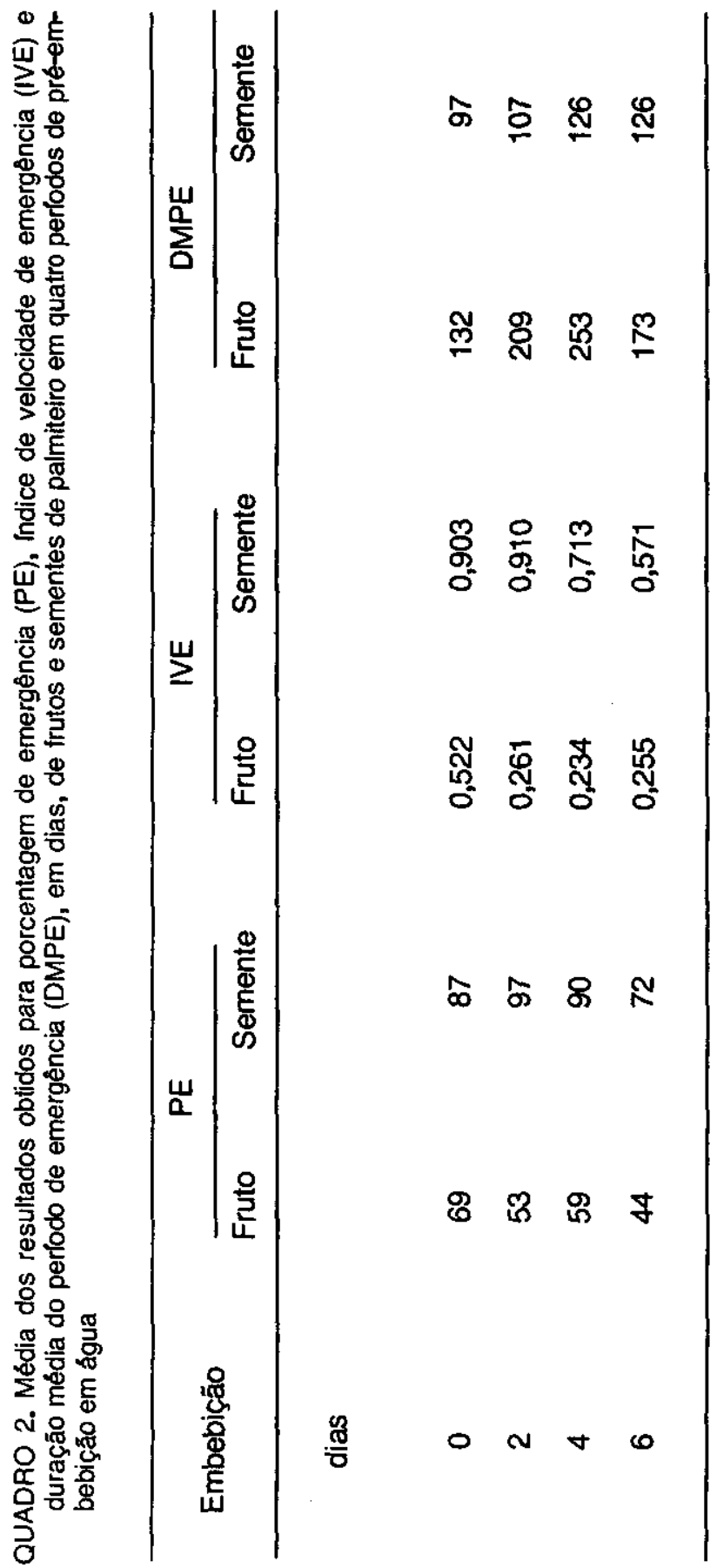


Dada a significância da decomposição do fator embebição dentro de fruto e semente, para a maior parte dos caracteres, e a presença de quatro niveis desse fator espaçados regularmente, foi possivel fazer a decomposição em seus efeitos lineares, quadráticos e cúbicos, através de polinômios ortogonais, e realizar $O$ teste da significância desses efeitos através do teste $F$.

A decomposição do tempo de embebição em componentes linear e quadrático foi significativa, pelo teste $F$, para a maior parte dos caracteres estudados, exceto para a porcentagem de emergência dos frutos e para a duração média do período de emergência de sementes, onde apenas o efeito linear foi significativo. O efeito cúbico mostrou significância somente para a duração média do periodo de emergência de frutos de palmiteiro. No entanto, o efeito quadrático apresentou o maior peso na funçāo de ajuste. A decomposiçāo dos efeitos é mais facilmente visualizada em gráficos, onde se pode, comparativamente, avaliar a influência dos diferentes periodos de pré-embebição em água na porcentagem e velocidade de emergência de frutos e sementes dessa palmeira.

A figura 1 mostra os efeitos linear e quadrático da porcentagem de emergência de frutos e sementes respectivamente. $O$ efeito linear para frutos inteiros, embora significativo, apresentou coeficiente de determinação de apenas

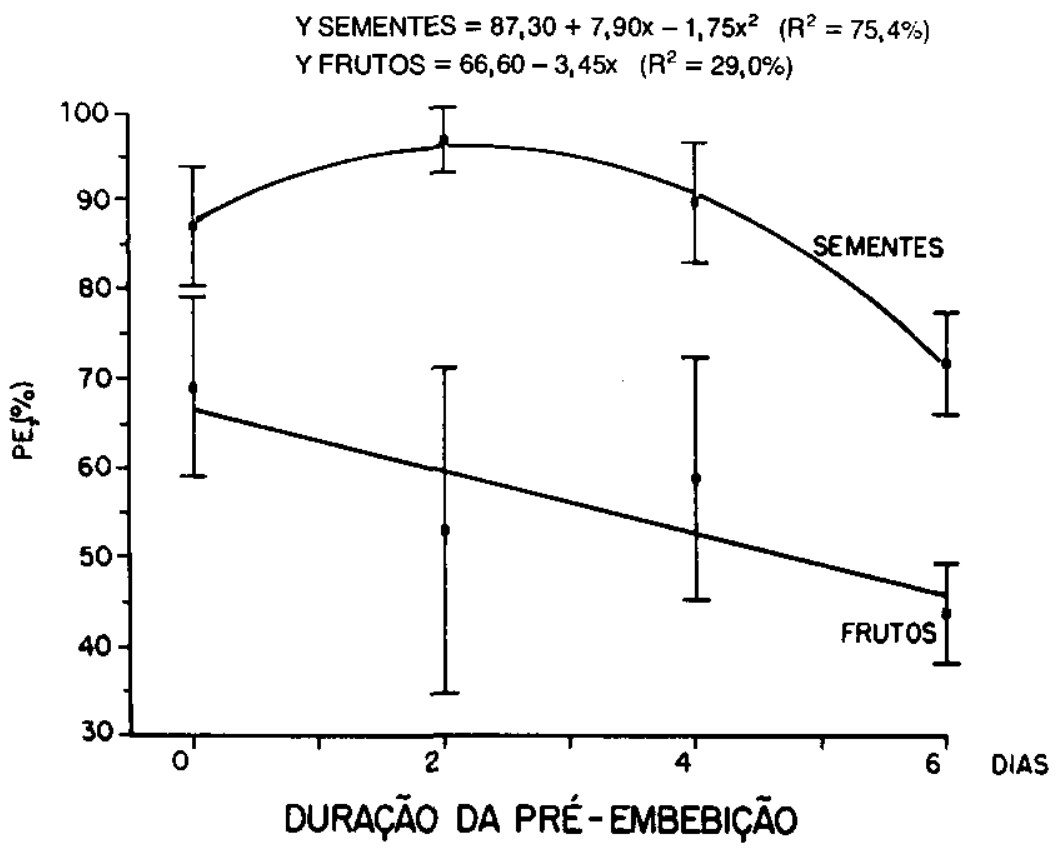

FIGURA 1. Porcentagem de emergência (PE) para frutos e sementes de palmiteiro submetidos a quatro perfodos de prê-embebiçăo em água. Barras verticais representam o desvio padrăo. 
29,0\%. A grande dispersão dos dados, avaliada pelo desvio padrão expresso na figura, é, com certeza, o fator responsável pelo mau ajuste. Por sua vez, a porcentagem de emergência a partir de frutos despolpados revelou valores significativos para o efeito quadrático (coeficiente de determinaçāo de $75,4 \%$ ). A análise conjunta dos dois tipos evidencia que a pré-embebiçāo foi prejudicial à emergência de plântulas de palmiteiro quando utilizadas sementes com a polpa do fruto, e que houve um efeito benéfico da embebição por dois dias, sobre esse mesmo caráter, para as sementes despolpadas. Após esse periodo, para tais sementes, ocorreu um decréscimo da porcentagem de emergência obtida, sendo esse decréscimo maior para a duraçāo de pré-embebiçāo de seis dias.

A figura 2 apresenta a velocidade de emergência pelo índice IVE para frutos e sementes. $O$ modelo quadrático explica melhor a variação encontrada

Y SEMENTES $=0,9159-0,0039 x-0,0093 x^{2} \quad\left(R^{2}=83,1 \%\right)$

Y FRUTOS $=0,5126-0,1473 x+0,0176 x^{2} \quad\left(R^{2}=75,8 \%\right)$

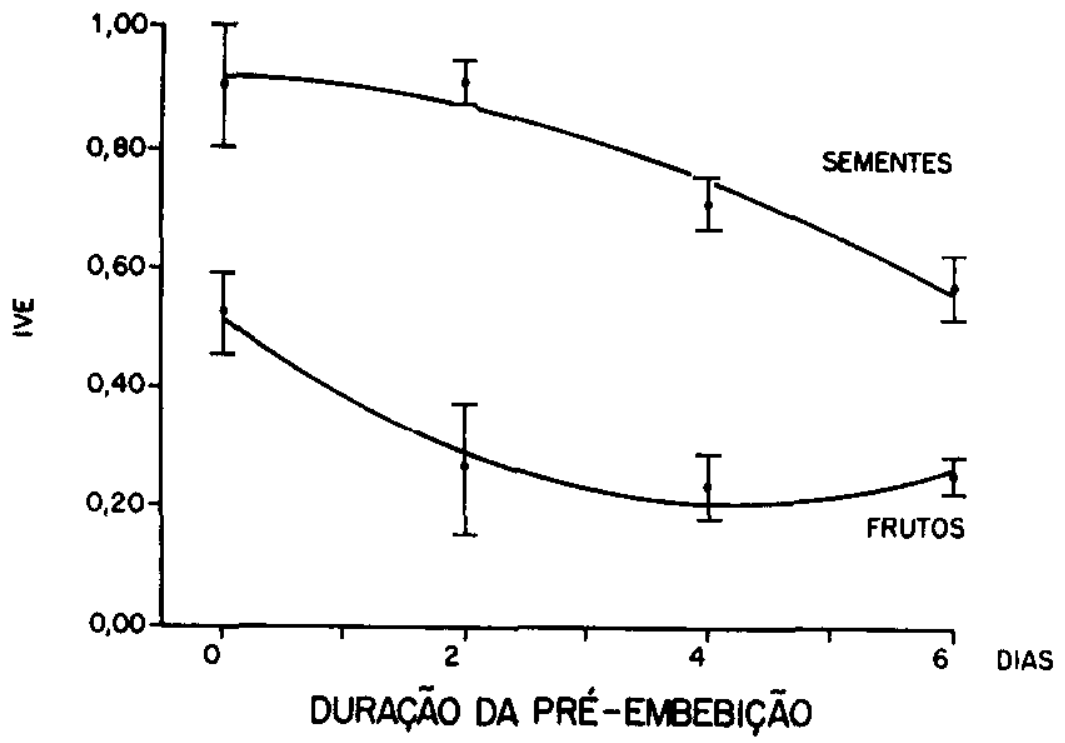

FIGURA 2. Índice de velocidade de emergência (IVE) para frutos e sementes de palmiteiro submetidos a quatro perfodos de pré-embebição em água. Barras verticais representam o desvio padrăo. 
tanto para frutos como para sementes, com coeficiente de determinação de 75,8 e $83,1 \%$ respectivamente. Para frutos e sementes, a maior velocidade de emergência foi obtida sem pré-embebição ( 0 dia). A velocidade de emergência caiu abruptamente após dois dias de embebição das sementes. Não obstante, para frutos, houve um rápido decréscimo de zero a quatro dias de embebição e uma estabilização da velocidade de emergência entre quatro e seis dias.

A duração média do período de emergência (DMPE) mostrou um ajuste quadrático para frutos e linear para sementes - Figura 3. A duração do período médio de emergência aumentou progressivamente com o tempo de pré-embebição para sementes e frutos, diferindo, este último, por um menor periodo do tratamento de 6 dias sobre 0 de 4 dias de pré-embebição. Não foi possivel encontrar explicações plausiveis para a menor duração do periodo de emergência de frutos pré-embebidos por 6 dias em relação aos imersos em água por 4 dias. Os coeficientes de determinação para esse caráter foram de $84,7 \%$ para frutos e $75,9 \%$ para sementes.

$$
\begin{aligned}
& \text { Y SEMENTES }=97,80+5,42 x \quad\left(R^{2}=75,9 \%\right) \\
& \text { Y FRUTOS }=127,69+67,08 x-9,78 x^{2} \quad\left(R^{2}=84,7 \%\right)
\end{aligned}
$$

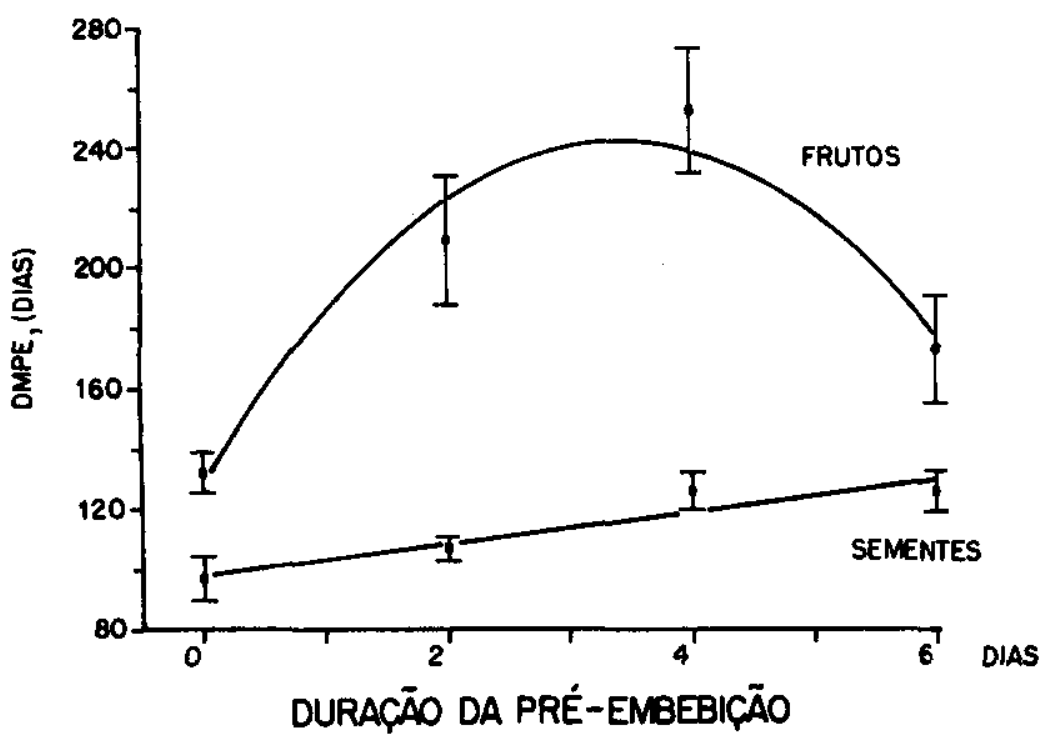

FIGURA 3. Duraçăo média do perfodo de emergência (DMPE), em dias, para frutos e sementes de palmiteiro submetidos a quatro perfodos de pre-mbebiçăo em água. Barras verticais representam o desvio padrão. 


\section{DISCUSSÃO}

Ratificando os resultados obtidos em ensaios anteriores (BOVI \& CARDOSO, 1976a, b, 1978), o presente experimento mostrou também maior porcentagem e velocidade de emergência de frutos despolpados (sementes) em relação à de frutos inteiros (sementes com a polpa) de palmiteiro. A redução da porcentagem de emergência, quando do uso de frutos inteiros, foi da ordem de 20 a $38 \%$ em relação àquela obtida para sementes sob idênticos períodos de pré embebição (Quadro 2). Considerando a velocidade de emergência, obtida através do indice proposto por MAGUIRE (1962) (IVE), frutos inteiros mostraram menor velocidade de emergência, apresentando uma redução de 42 a $71 \%$ em relação àquela obtida quando do uso de frutos despolpados. A menor diferença entre os dois materiais de propagação foi observada quando não houve pré-embebição em água (0 dia), enquanto a maior foi alcançada no periodo de pré-embebição de dois dias.

O efeito benéfico do simples despolpamento pôde também ser observado em relação à duração média do periodo de emergência. Para frutos, esse período foi cerca de 132 a 253 dias para as diferentes duraçōes do tratamento de pré-embebiçāo, e em tomo de 97 a 126 dias para sementes. O uso de sementes despolpadas reduziu o período médio de emergência em cerca de 27 a $50 \%$ daquele obtido para frutos inteiros, encontrando-se as maiores reduçöes nos periodos de dois a quatro dias de pré-embebição em água. Portanto, de forma geral, o simples despolpamento do fruto acarretou maior e mais rápida emergência de sementes de palmiteiro.

A pré-embebição em água à temperatura ambiente por dois dias mostrou efeito benéfico na porcentagem de emergência de sementes, mas não na de frutos. Embora a água tenha sido trocada diariamente, aventa-se que a menor porcentagem de emergência dos frutos que sofreram préembebiçāo em relaçāo ao tratamento controle (frutos - 0 dia) deva-se a facilidade de desenvolvimento de microorganismos fitopatogênicos na polpa do fruto, que a alta umidade propicia, e que poderiam afetar a semente. Segundo FARRANT et al. (1988), quando sementes recalcitrantes são armazenadas à temperatura ambiente e em estado de completa embebição, normalmente ocorre contaminação por microorganismos. $O$ tratamento fungicida efetuado, por ser superficial e facilmente lavado após a semeadura pela irrigação subseqüente, nāo foi provavelmente efetivo para controlar os fungos que se desenvolveram na polpa dos frutos (e no endocarpo fibroso que reveste a semente), ou pode ter havido, separada ou concomitantemente, ataque de bactérias.

Embora a pré-embebição em água por dois dias tenha sido benéfica à emergência de sementes de palmiteiro, não acelerou a rapidez ou velocidade de emergência. Na verdade, o período médio de emergência durou dez dias a mais no tratamento de embebição por dois dias quando comparado ao sem embebição. 


\section{CONCLUSÕES}

1. O despolpamento do fruto acelerou e aumentou a emergência de sementes de palmiteiro, diminuindo o tempo médio do processo germinativo.

2. A pré-embebição do fruto foi prejudicial à porcentagem final e velocidade de emergência.

3. A pré-embebição de sementes por dois dias mostrou efeito benéfico sobre a porcentagem final, nāo sendo, entretanto, efetiva para acelerar a velocidade de emergência de sementes dessa palmeira.

\section{AGRADECIMENTOS}

A autora agradece aos pesquisadores cientificos Violeta Nagai e Toshio Igue, da Seção de Técnica Experimental e Cálculo do IAC, a sugestão das análises estatísticas e a revisão técnica do manuscrito.

\section{REFERÉNCIAS BIBLIOGRÁFICAS}

ADRIANCE, G.W. \& BRISON, F.R. Propagation of horticultural plants. 2ed. Bombay Tata, McGraw-Hill, 1967. 289p.

BIANCHETTI, A. \& AMARAL, E. Dia médio e velocidade de germinaçāo de sementes de cebola (Allium cepa L.). Pesquisa Agropecuária Brasileira, Braslia, 13(1):33-44, 1978.

BOVI, M.L.A. Palmito. In: CAMPINAS. Instituto Agronómico. Instruçōes agrícolas para 0 Estado de Sáo Paulo. 3ed. Campinas, 1986. p.164. (Boletim, 200)

\& CARDOSO, M. Conservaçăo de sementes de palmiteiro (Euterpe edulis Mart.). Bragantia, Campinas, 37:65-71, 1978.

\& - Germinaçăo de sementes de palmiteiro (Euterpe edulis Mart.). II. Bragantia, Campinas, 35:23-29, 1976a.

$\&$ - Profundidade de semeadura de palmiteiro. Bragantia, Campinas, 35:161-167, 1976b.

FARRANT, J.M.; PAMMENTER, N.W. \& BERJAK, P. Recalcitrance - a current assessment. Seed Science \& Technology, Zürich, 16:155-166, 1988.

FIGUEIREDO, F.J.C.; MULLER, C.H.; MULLER, A.A.; FRAZĀO, D.A.C. \& PEREIRA, L.A.F. Tratamentos ffsicos na germinação de Castanha-do Brasil. Belém, EMBRAPA-CPATU, 1980. 13p. (Boletim de Pesquisa, 12)

GOMES, F.P. Curso de estatistica experimental. 12ed. Piracicaba, Nobel, 1987. 467p. HARTMANN, H.T. \& KESTER, D.E. Plant propagation: principles and practices. 3ed. Englewood Cliffs, Prentice-Hall, 1975. 662p. 
LEĀO, M. \& CARDOSO, M. Instruçбes sobre o cultivo do palmiteiro. Campinas, IACSUDELPA, 1974. $18 p$.

MADHAVA RAO, V.N. \& HASSAN, M.V. Studies on seeds viability in cashew. Indian Journal of Agricuttural Science, New Delhi, 27(3):289-294, 1957.

MAGUIRE, J.D. Speed of germination - aid in selection and evaluation for seedling emergence and vigor. Crop Science, Madison, Wis., 2(2):176-177, 1962.

MORAES, V.H. de F. \& MULLER, C.H. Influência da casca e da injeçáo de ácido qiberélico na absorçáo de água pelas sementes da castanheira (Bertholletia excelsa H.B.K.). Belém, EMBRAPA-CPATU, 1978. 7p. (Comunicado técnico, 2)

STEEL, R.G.D. \& TORRIE, J.H. Principles and procedures of statistics: a biometrical approach, 2ed. New York, McGraw-Hill, 1980, 631p. 